\title{
Hospitals are dangerous places
}

Adrian G Barnett, Nicholas Graves, Ben S Cooper, Rahul Batra and Jonathan D Edgeworth

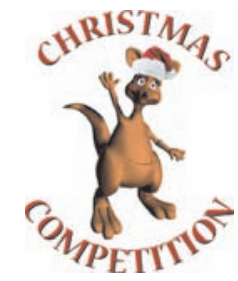

L

ength of stay in the intensive care unit (ICU) is a complex variable with many contributing factors, including primary diagnosis, comorbidities and adverse events such as health care-acquired infection. The risk of an adverse event increases on weekends when staff availability is lower. We aimed to assess the effect of day of the week on patients' odds of being discharged alive from the ICU, while controlling for other determinants of length of stay.

\section{METHODS}

We studied 4569 patients admitted to the ICU of St Thomas' Hospital, London, from 2002 to 2006. For each patient, we had the date of admission to and discharge from the ICU. We modelled the probability of discharge using a longitudinal survival model. ${ }^{1}$ Patients who died were censored. We modelled day of the week as a categorical variable, with Wednesday as the reference category. The model controlled for age, APACHE II (Acute Physiology and Chronic Health Evaluation) score, whether the patient was being filtrated or ventilated, and presence of health care-acquired infection. Software from the BUGS (Bayesian inference Using Gibbs Sampling) Project ${ }^{2}$ was used for the analysis.

\section{RESULTS}

The odds of being discharged by day of the week are shown in the Box. The odds of being discharged alive were significantly lower on Sunday and significantly higher on Friday (the $95 \%$ posterior interval for these 2 days does not include 1 ).

\section{DISCUSSION}

Our results show a frightening pattern of discharge from an ICU ward. The causes are most likely a complex web of specialist availability and patient requests to be home for the weekend. During the week, discharges run as smooth as silk, but things spin out of control at the start of the weekend. This problem has crept undetected into the St Thomas' Hospital system; removing it may require sweeping changes to staff rosters.

\section{COMPETING INTERESTS}

None identified.

\section{ABSTRACT}

Objective: To estimate the effect of day of the week on the odds of being discharged alive from an intensive care unit (ICU).

Design: A longitudinal analysis of risk of discharge by day of the week.

Setting and patients: 4569 patients admitted to the ICU of St Thomas' Hospital, London, from 2002 to 2006.

Results: The odds of being discharged alive were lowest on the weekend and literally climbed during the week.

Conclusion: Our results show a frightening pattern of discharge from an ICU ward, most likely caused by a complex web of specialist availability and patient demand.

MJA 2008; 189: 672

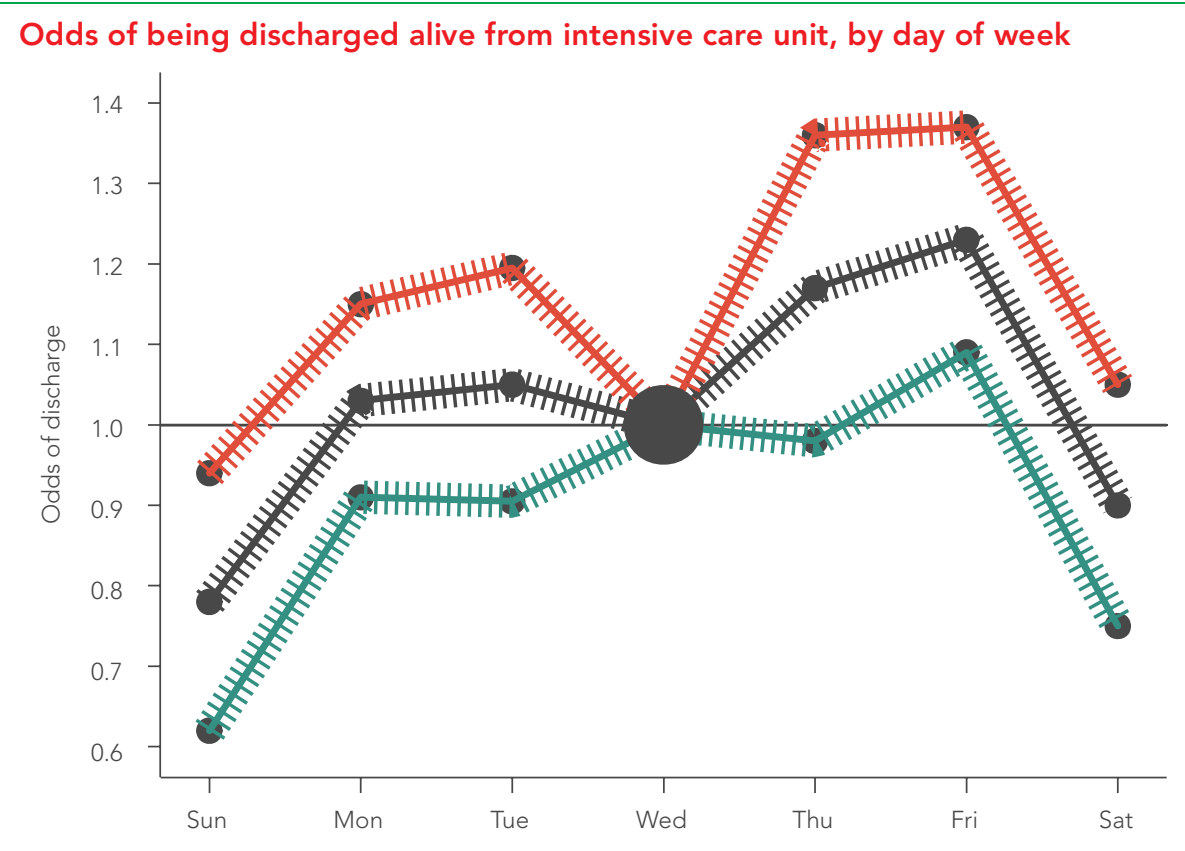

Black line represents the mean; red and green lines show the $95 \%$ posterior interval. The reference day of Wednesday is represented by a large dot.

\section{AUTHOR DETAILS}

Adrian G Barnett, BSc(Hons), GStat, PhD(Maths), Statistician ${ }^{1}$

Nicholas Graves, BA(Hons), MA, PhD(Econ), Associate Professor in Health Economics ${ }^{1}$

Ben S Cooper, BSc, MSc, PhD, Mathematical Modeller²

Rahul Batra, BS, MD, Infectious Diseases Clinical Research Fellow ${ }^{3}$

Jonathan D Edgeworth, MB BChir, BSc, PhD, Consultant Microbiologist ${ }^{3}$

1 Institute of Health and Biomedical Innovation, Queensland University of Technology,

Brisbane, QLD.
2 Statistics, Modelling, and Bioinformatics Department, Centre for Infections, Health Protection Agency, London, UK.

3 Guy's and St Thomas' National Health Service Foundation Trust, London, UK.

Correspondence: a.barnett@qut.edu.au

\section{REFERENCES}

1 Hedeker D, Gibbons RD. Longitudinal data analysis. Hoboken, NJ: Wiley, 2006.

2 Spiegelhalter DJ, Thomas A, Best NG, et al. WinBUGS version 1.4 .3 user manual. Cambridge: MRC Biostatistics Unit, 2007.

(Received 17 Oct 2008, accepted 22 Oct 2008) 